\title{
Microstructure Changes and Steady State Creep Characteristics in the Superplastic Sn-5wt.\% Bi alloy During Transition.
}

\author{
B.A.Khalifa, M.R.Nagy*, G.S.Al-Ganainy and R.Afify. \\ Physics Dept. Faculty of Science, Ain Shams University, Cairo, Egypt. \\ *Physics Dept.Faculty of Education,Ain Shams University,Cairo,Egypt.
}

Creep tests of Sn-5wt.\%Bi alloy have been studied at different creep temperatures between (308-388K) and at three constant applied stresses of values 20.5, 21.7 and 23 MPa. Superplastic flow was found to be based on the steady state law of creep with the incorporation of grain size effect. In the steady state deformation, the flow stress $(\sigma)$ was found to depend on strain rates $\left(\dot{\varepsilon}_{s t}\right)$ and temperatures. The steady state creep of $\mathrm{Sn}-5 \mathrm{wt} . \% \mathrm{Bi}$ has been investigated within the temperature range from (308-388K), and the strain rate sensitivity parameters $(m=\partial \ln \sigma / \partial \ln \dot{\varepsilon})$ were calculated at different temperatures; they indicated two transition temperatures at "328 and $361 \mathrm{~K}$. The strain sensitivity parameters were found to be shifted to higher values with increasing temperatures or decreasing grain diameters. The energies activating creep calculated in the three ranges of temperatures were found to have the values "37.16 $\pm 3 \mathrm{KJ} / \mathrm{mole}$ " in the first range of temperature (308-328K) and " $50.41 \pm 5 \mathrm{KJ} / \mathrm{mole}$ " in the intermediate range of temperature (338-361K) and "72.02 $\pm 7 \mathrm{KJ} /$ mole in the third range of temperature (361-388K) respectively. The values of the activation energies in the first and the intermediate ranges of temperatures suggest the grain boundary sliding with partially diffusion mechanisms while in the third range one it might be due to the cross slipping mechanism. Metallurgical observations and grain diameter measurements confirmed these mechanisms as well as the above two transition temperatures. The $x$-ray structure analysis through the measurements of the lattice constants ( $a$ and $c$ ), the ratios (c/a), the half line widths ( $\Delta 2 \theta)$, the integral intensities (I) and the residual lattice strains $\left(\frac{\Delta a}{a}\right.$ and $\frac{\Delta c}{c}$ ) for the Sn-matrix, exhibited peaks at the two transition temperatures. 


\section{Introduction:}

Superplasticity is shown by materials with a fine grain size, usually less than $10 \mu \mathrm{m}$ when they are deformed within strain rate range of $10^{-5}$ to $10^{-1}$ at temperature higher than $0.5 T_{m}$, where $T_{m}$ is the melting temperature [1].

The phenomenon of superplasticity lies in its extreme elongation for samples pulled under tension, which could be reached to 5500\% [2]. Hines and Chokshi [3] had reviewed two main types of superplasticity behaviors which are named as micrograin or microstructure plasticity and transformation or environmental superplasticity. The strain sensitivity $(\mathrm{m}=\partial \ln \sigma / \partial \ln \dot{\varepsilon})$ has been used as a parameter to evaluate superplasticity, where $(\sigma)$ is the flow stress and $(\dot{\varepsilon})$ is the strain -rate [4]. Cline and Alden [5] showed that the high rate sensitivity parameter and superplasticity occurred at intermediate strain rates in fine-grained materials and they believed that it is associated with a transition. They also reported that the transition temperature was shifted to higher strain- rate value with increasing temperature or decreasing grain size. They presumed that the high rate mechanism is slip, and suggested that the low rate mechanism is grain boundary sliding. Alden [6] studied the plastic deformation processes in an extruded Sn-5wt.\%Bi alloy by means of mechanical measurements and microstructure observations and concluded that the flow stress and strain-rate sensitivity of the flow stress are strong functions of both strain-rate and Sn-grain size. Guthrie et al [7] studied the superplasticity in ternary "Pb-Bi-Sn" alloy and in binary alloys of $\mathrm{Sn}-\mathrm{Bi}, \mathrm{Sn}-\mathrm{Pb}$ and showed the superplastic properties occurred at high strain rate and explained the behavior as due to small grain sizes and low melting temperatures. Mechanical tests had been performed on the superplastic Sn-5wt.\%Bi alloy by Valiyev et al [8] under various conditions of deformations such as short time loading with increasing strain rates and rapid release of the load. Variation in creep properties were studied by Saad [9] using Sn-0.5at.\%Bi alloy samples of various grain diameter and indicated a decrease in the steady-state creep rates and an increase in the activation volumes as the grain diameters were increased. Under the condition of the superplasticity of Sn-Bi alloy, examination of hardening were done by Larin et al [10]. They proposed a theoretical model to describe the dependence of flow stress $(\sigma)$, grain size (D) and strain rate $(\dot{\varepsilon})$ on the degree of deformation $(\varepsilon)$ of single and quasi single phase of commercial alloy having $(\varepsilon)$ corresponding to superplasticity stages and obtained good agreement with experimental results.

Pattanaike [11] had made a series of experiments on Sn-Bi solder in an attempt to characterize its mechanical behavior including tensile tests over different ranges of strain-rates and the steady state stresses. and to obtain a relation between them. 
Sueyoshi and Ohzono [12] studied the hardness, microstructure, surface morphology and machinability of Sn-Bi alloy and found that the microstructure was dependent upon solidification.

The activation energies for steady state creep in the Sn-5wt.\%Bi alloy were studied by Al-Ganainy et al [13] in the vicinity of the transformation temperature (328K) and above it and found to be 62 and $87 \mathrm{KJ} / \mathrm{mole}$ respectively and characterized them by the grain boundary sliding (G.B.S.) mechanism. The same authors [14] studied the steady state creep in the case of Sn-1wt.\%Pb alloy in low and high ranges of temperatures and obtained the activation energies with values of 37.2 and $57 \mathrm{KJ} / \mathrm{mole}$ respectively and explained these values again by grain boundary sliding mechanism.

Steady state creep of $\mathrm{Sn}-1 \mathrm{wt} . \% \mathrm{Bi}, \mathrm{Sn}-2 \mathrm{wt} . \% \mathrm{Bi}$ and $\mathrm{Sn}-5 \mathrm{wt} . \% \mathrm{Bi}$ as a function of stress and temperature were studied by Milten et al [15] and obtained an empirical equation to show the linear dependence at low strain rate and an exponential stress dependence at high strain rate. Their observations suggested that dislocation climb was the active mechanism in the nonlinear region. They also found that the stress sensitivity of the steady state was similar to that of pure "Sn" and the addition of "Bi" had decreased the steady-state creep rates.

The aim of the present work is to study the influence of phase transition temperatures on both mechanical and microstructure changes for the superplastic Sn-5wt.\%Bi alloy samples during and after creep deformations.

\section{Experimental Procedure:}

The superplastic Sn-5wt.\%Bi alloy samples were prepared by melting metals of tin and bismuth (purity 99.998\%) in graphite crucible together with chloride flux $\left(\mathrm{Ca} \mathrm{Cl}_{2}\right)$ to avoid oxidation. Casting in rod form was performed in a $25 \times 2 \times 2 \mathrm{~cm}$ graphite mold. To obtain the characteristic of superplasticity, the casting rod was annealed at 403K for 154 hours (about one week) [6], then the temperature was decreased slowly every ten minutes until $343 \mathrm{~K}$, and finally quenched in liquid nitrogen with rate of cooling of $18.4 \mathrm{~K} / \mathrm{sec}$. The casting rod was then swaged in the form of a wire with diameter of $1 \mathrm{~mm}$. This wire was then cut to pieces each of $4 \mathrm{~cm}$ long and annealed at $353 \mathrm{~K}$ for 5 minutes followed by quenching in liquid nitrogen with the same rate of cooling. This procedure was done to eliminate cold working effect introduced during swaging in wire form and to minimize the high extensions character of superplastic material for the purpose of this work. 
Creep deformations on the alloy wire samples were operated by using an apparatus locally manufactured. The surface of the tested wire was examined by metallurgical microscope to ensure that it is free from cracks or any other defects. The wire under creep test was clamped between two grips and kept at the desired temperature by means of tubular furnace which has been calibrated to ensure uniform region of stable zone of $3 \mathrm{~cm}$ in length. The effective length exhibiting elongation here was $0.4 \mathrm{~cm}$ long. A sensor thermocouple was placed in direct contact with the test wire at suitable position. The creep temperatures were performed in the range between (308-388K) and kept constant within " $\pm 2^{0} K$ ” over the whole tests. Suitable constant applied stress was used and the elongation was calculated every one minute till fracture.

The morphological appearance was studied by Nickon metallurgical microscope and the grain diameters of the crept alloy wires under different creep temperatures were measured by the line intercept method [16].

The structure characteristic of the deformed alloy wires under the constant applied stresses and the different creep temperatures as well as the undeformed wires were investigated by $\mathrm{x}$-ray diffractometer technique at room temperature. The $\mathrm{x}$-ray lattice parameters were calculated by least square method to follow the changes occurred in the alloy samples.

The broadening in the x-ray profiles due to size effect was calculated from the line breadth at half intensity maximum using the relation [17]:

$$
\beta=\frac{K \lambda}{t \cos \theta}
$$

where " $\beta$ " is the measured breadth at half intensity maximum in radian, $\mathrm{t}$ is the linear dimension of the crystallite, $\lambda$ is the $\mathrm{x}$-ray wavelength, $2 \theta$ is the Bragg angle and $\mathrm{K}$ is constant. The integrated intensity for each reflection was calculated from the area under the x-ray profile peak.

\section{Experimental Results and Discussion:}

A typical set of creep observations for identical wire samples of Sn-5wt.\%Bi alloy which were obtained under three constant applied stresses of 20.5, 21.7 and $23 \mathrm{MPa}$ and at different creep temperatures in the range of (308-388K), are illustrated in Fig.(1a,b,c). From these curves, it is noted that while the stresses and temperatures were increasing, the duration of time to fracture was decreased. The slopes of the linear parts of these curves, which are known as the steady state strain- rates $\left(\dot{\varepsilon}_{s t}\right)$, were found to be dependent on both constant applied stresses and the creep temperatures. The relation between 
the calculated values of $\left(\dot{\varepsilon}_{\text {st }}\right)$ as a function of creep temperatures at the three constant applied stresses is illustrated in Fig.(2). The increase in the $\left(\dot{\varepsilon}_{s t}\right)$ with the effect of both creep temperatures and the constant applied stresses has occurred within three stages of temperatures. In the first range from (308-328K) and according to the phase diagram given in Fig.(3), the Sn-5wt.\%Bi alloy shows " $\alpha$-phase" (rich in $\mathrm{Bi})+$ Sn-matrix. The second range from (338-361K) indicates " $\alpha$-phase” (rich in $\mathrm{Bi}$ ) + " $\beta$-phase” (rich in $\mathrm{Sn}$ ). The third range from (361-388K) presents solid solution of single phase " $\beta$-phase”, which has occurred due to solving of the " $\alpha$-phase" and converting it to solid solution. This process reduces the obstacles, increases the diffusion process and hence increases the strain. The dependence of the " $\dot{\varepsilon}_{s t}$ " on the applied stress “ $\sigma$ ”, was found to obey the relation [18]:

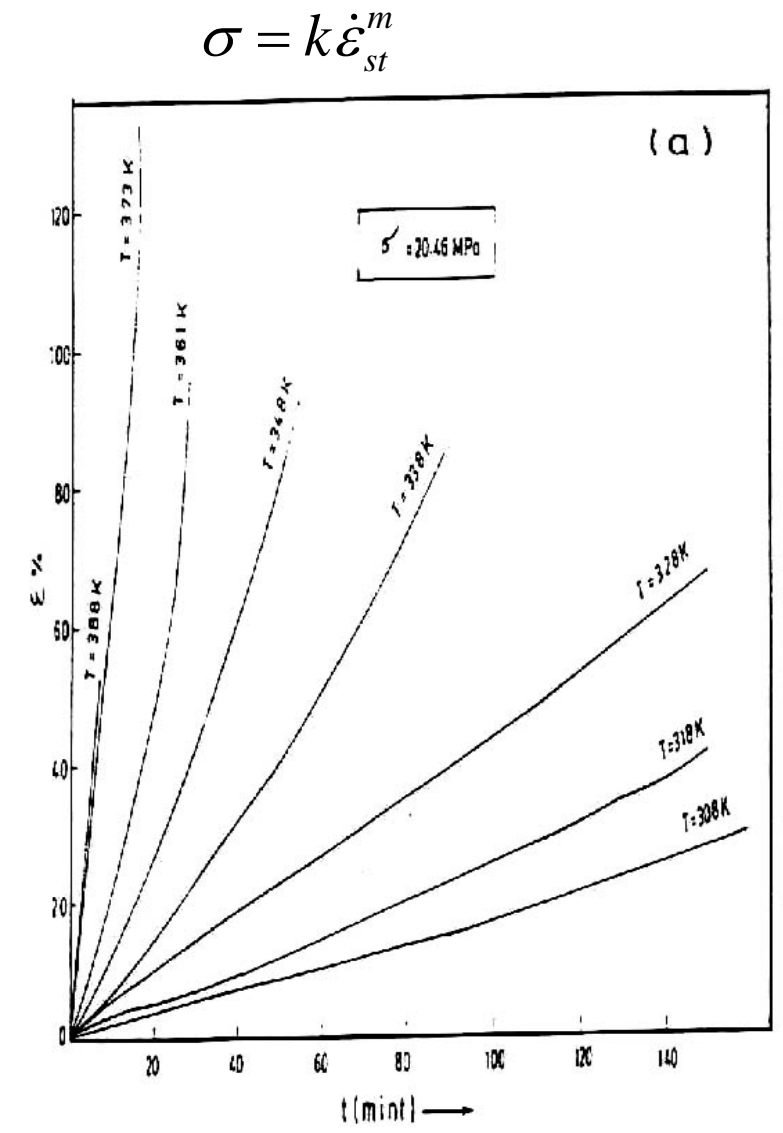

Fig.(1) : The creep curves of Sn-5wt.\%Bi alloy under constant applied stresses 20.5,21.7, $23 \mathrm{MPa}$ and at different creep temperatures. 


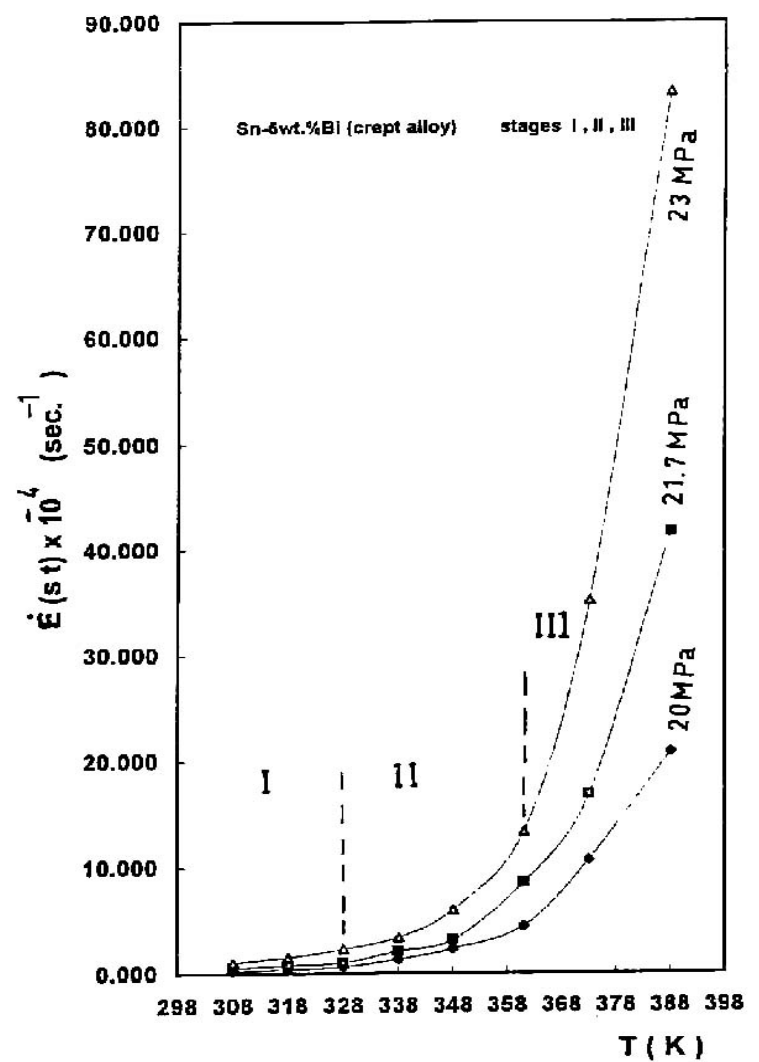

Fig.(2) : The relation between strain rate “ $\dot{\varepsilon}_{s t}$ ” as a function of creep temperatures for Sn-5wt.\%Bi alloy.

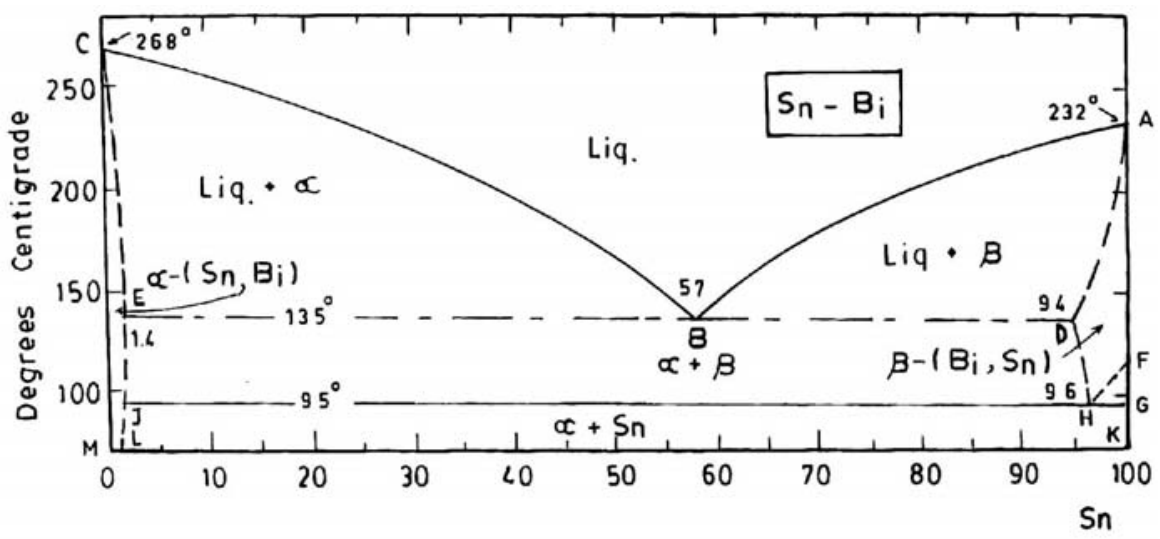

Fig.(3): Phase diagram of "Tin-Bismuth" system. 
where $\mathrm{k}$ is constant and the exponent " $\mathrm{m}$ ", which is dependent on the testing conditions, is known as the strain-rate sensitivity parameter " $m=\partial \ln \sigma / \partial \ln \dot{\varepsilon}_{s t}$ ". The strain-rate sensitivity parameters " $m$ ", which were derived from the slopes of the straight lines relating " $\ln \sigma$ " versus " $\ln \dot{\varepsilon}_{\text {st }}$ " (Fig.(4a)) after making the best fitting lines by least square method, as function of creep temperatures are illustrated in Fig.(4b). This figure shows the values of " $\mathrm{m}$ " at the first transition temperature " $328 \mathrm{~K}$ " as " $0.0672 \pm 0.002$ " and at the second transition temperature " $361 \mathrm{~K}$ " as " $0.1037 \pm 0.002$ ". These values indicate that the dominant mechanism is dislocation mechanism [19]. These strain-rate sensitivity parameter values highly confirmed the previously explained three stages.

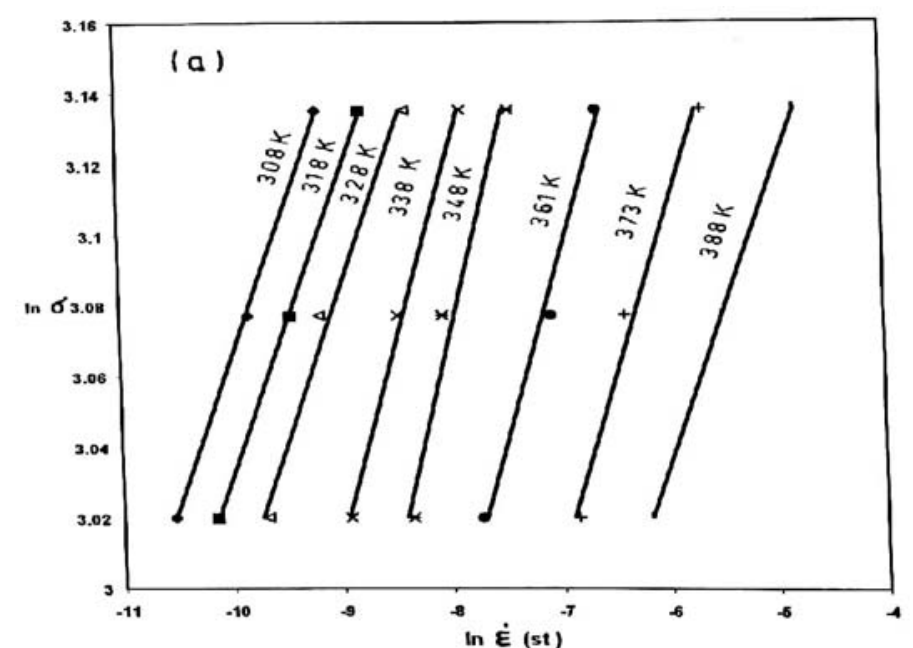

Fig.(4a) : Strain rate-stress relationship at different creep temperatures for Sn-wt.\%Bi alloy.

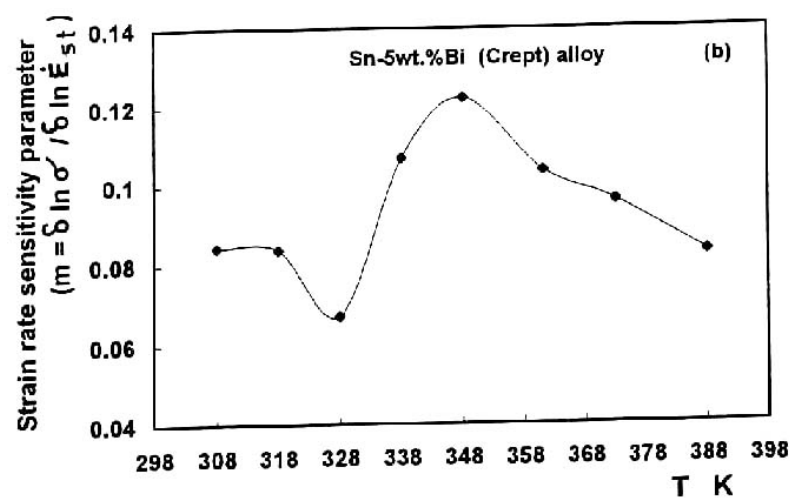

Fig.(4b) : Strain rate sensitivity parameter " $m=\partial \ln \sigma / \partial \ln \dot{\varepsilon}_{\text {st }}$ " as a function of creep temperatures for $\mathrm{Sn}-5 \mathrm{wt} . \% \mathrm{Bi}$ alloy. 
The activation energies of the steady state creep " $Q_{s t}$ ” were calculated according to Arhenius equation [20] of the form:

$$
\dot{\varepsilon}_{s t}=C e^{-Q_{s t / K T}}
$$

where $\mathrm{C}$ is constant, $\mathrm{K}$ is the Boltzmann constant and $\mathrm{T}$ is the creep temperatures. The activation energy values were calculated from the slopes of the straight lines relating " $\ln \dot{\varepsilon}_{\text {st }}$ " versus $1000 / \mathrm{T}\left(K^{-1}\right)$ at the three constant applied stresses and at the three different stages (Fig.(5)). The activation energy values at the three stages, were found to be " $37.16 \pm 3$, 50.41 \pm 5 and $72.0 \pm 7$ $\mathrm{KJ} /$ mole" respectively. The activation energies of the steady state creep " $Q_{s t}=37.16 \pm 3$ and $50.41 \pm 5 \mathrm{KJ} / \mathrm{mole"} \mathrm{occurred} \mathrm{in} \mathrm{the} \mathrm{first} \mathrm{and} \mathrm{the} \mathrm{second}$ stages are due to the grain boundary sliding mechanism [8, 14, 21, 22].
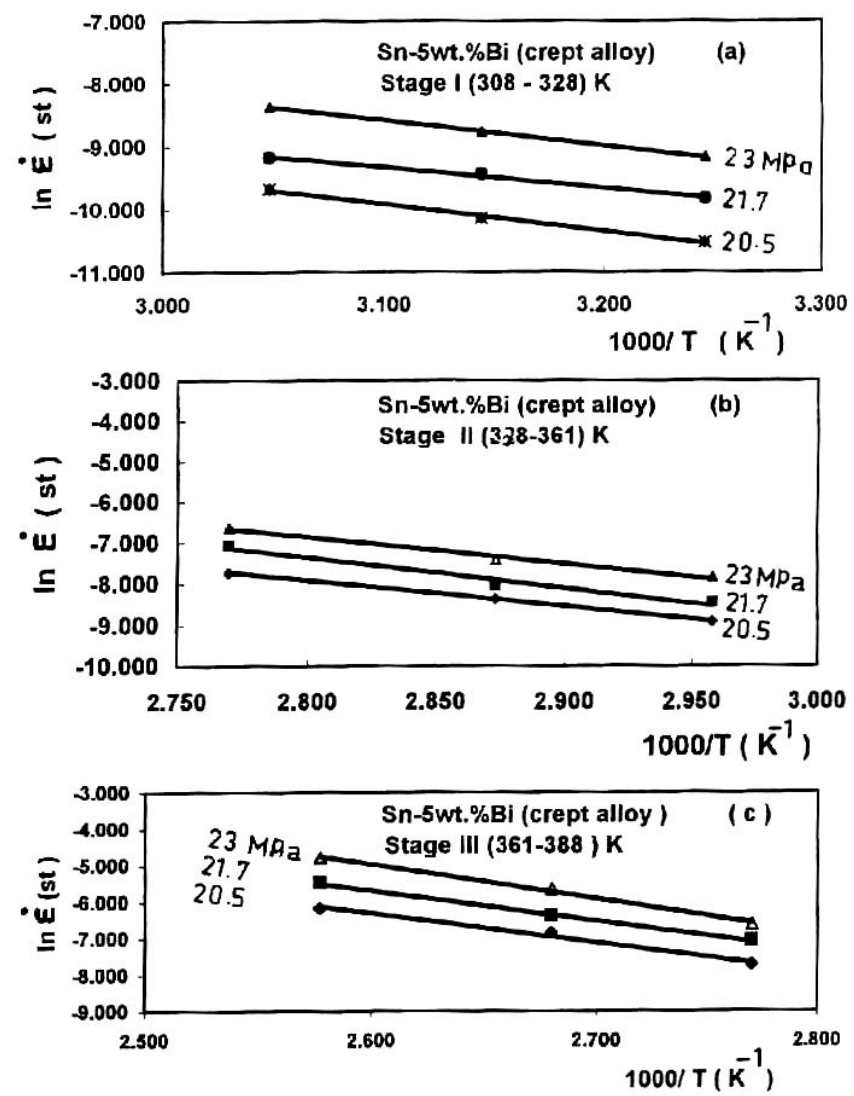

Fig.(5) : The relation between “ln $\dot{\varepsilon}_{\text {st }}$ and 1000/T ( $\left.K^{-1}\right)$ ” for Sn-5wt.\%Bi alloy. 
The third stage of temperature, where " $Q_{s t}=72.02 \pm 7 \mathrm{KJ} / \mathrm{mole}$ " was explained by cross slipping mechanism, which may be occurred due to the diffusion of $\mathrm{Bi}$ atoms to form homogeneous solid solution $\beta$-phase of the Snmatrix.

The metallurgical observations of the uncrept and crept samples deformed under constant applied stress of "20.5 MPa" and at different creep temperatures are reproduced in Fig. (6a). The average grain diameters at the three stages of the crept alloy are illustrated in Fig.(6b). The grain diameter was increasing gradually till maximum value of " $17.09 \mu \mathrm{m}$ " at " $328 \mathrm{~K}$ ", then decreased to " $12.96 \mu \mathrm{m}$ " at " $348 \mathrm{~K}$ " and finally increased to " $14.58 \mu \mathrm{m}$ " at " $361 \mathrm{~K}$ ". At higher temperature " $388 \mathrm{~K}$ ", the grain diameter has nearly the same value of the uncrept alloy $(13.85 \mu \mathrm{m})$. The grain diameter with its value of " $17.09 \mu \mathrm{m}$ " explains again the effect of G.B.S. mechanism with partial diffusion while the grain diameter having the value of " $14.58 \mu \mathrm{m}$ " shows that the dominant mechanism is the cross slipping beside small diffusion. The dependence of the grain diameter on the steady state strain-rate " $\dot{\varepsilon}_{s t}$ " is illustrated in Fig.(6c), which confirms the above mechanisms. Effect of aging times on the crept samples under constant applied stress of "21.7 MPa" (samples aged for three years) are illustrated in Fig.(7a). Relation between grain diameters and creep temperatures is shown in Fig.(7b).The effect of creep temperatures on both grain diameter and strain rate and effect aging time on grain diameter are illustrated in Table(1) for samples having initial values of G.D. as "13.85 $\mu \mathrm{m}$ ” and "38.07 $\mu \mathrm{m}$ (after 3 years)" respectively.

Table (1): Effect of creep temperatures on grain diameters and strain rate and effect of ageing time on grain diameters. Samples have initial G.D. values of $38.07 \mu \mathrm{m}$ and $13.85 \mu \mathrm{m}$ respectively.

\begin{tabular}{|c|c|c|}
\hline Creep temp. & G.D. $\mu \mathrm{m}$ & $\begin{array}{l}\text { Strain rate } \mathrm{X} \\
10^{-4}(\mathrm{~cm} / \mathrm{sec})\end{array}$ \\
\hline & Directly $\quad$ After 3 years ageing & \\
\hline 1 st stage & G.D. increased & $\begin{array}{l}\text { Very slow } \\
\text { increase }\end{array}$ \\
\hline $308-328 \mathrm{~K}$ & $25.4-37.22$ & $0.26-0.62$ \\
\hline 2 nd stage & $\begin{array}{l}\text { G.D. decreased } \\
\text { then increased }\end{array}$ & $\begin{array}{l}\text { More fast } \\
\text { increase }\end{array}$ \\
\hline $328-361 \mathrm{~K}$ & $17.1-12.96-14.6 \quad 37.22-26.81-30.56$ & $0.60-2.30$ \\
\hline 3 rd stage & G.D. slowly decreased & Rapid increase \\
\hline $361-388 \mathrm{~K}$ & $30.56-28.78$ & $14.3-20.8$ \\
\hline
\end{tabular}


The $\mathrm{x}$-ray diffraction profiles obtained for the undeformed and deformed wire alloy samples at room temperature are illustrated in Fig.(8). The alloy samples were deformed at the stress $23 \mathrm{MPa}$ and at different creep temperatures in the range of $308-388 \mathrm{~K}$. The $\mathrm{x}$-ray analysis indicated only the presence of Sn-matrix. The variations in the lattice parameter "a" for the crept samples were found to decrease gradually from " $5.849 \pm .002 \mathrm{~A}$ " to " $5.822 \pm .004 \mathrm{~A}$ " in the first range of temperature, then increased to " $5.844 \pm .002 \mathrm{~A}$ " at $348 \mathrm{~K}$ followed by another decrease to " $5.827 \pm .017 \mathrm{~A}$ " at $361 \mathrm{~K}$. Finally, in the third range, it increased to reach the value of the uncrept sample " $5.843 \pm .003 \mathrm{~A}$ " (Fig.(9a)). The relation between the creep temperatures and the residual lattice strain " $\frac{\Delta a}{a}$ ” is illustrated in Fig.(9b), which confirms the same behavior. The lattice parameter " $\mathrm{c}$ " and the residual lattice strain in the cdirection " $\frac{\Delta c}{c}$ ” are represented in Fig.(10a,b). Their values decreased to minimum values at $328 \mathrm{~K}$ in the same way as the parameters "a, $\frac{\Delta a}{a}$ ”, then increased to their maximum values at $361 \mathrm{~K}$. Such behavior may be explained as follows:

(i) In the first range of the creep temperatures, both lattice parameters "a, c" as well as the residual strains " $\frac{\Delta a}{a}, \frac{\Delta c}{c}$ ” decreased to minimum values, where some of Sn-matrix was dissolved and the material indicated " $\alpha$-phase (rich in $\mathrm{Bi}$ ) + Sn-phase". (ii) In the second range of the creep temperatures, all parameters were increased gradually until the creep temperature reached 348K. From 348 to $361 \mathrm{~K}$, while both parameters "c, $\frac{\Delta c}{c}$ ” were continuing their increasing trend, the parameters "a, $\frac{\Delta a}{a}$ ” decreased to their minimum values. This indicates the formation of " $\alpha$-phase (rich in $\mathrm{Bi})+\beta$-phase (rich in $\mathrm{Sn}$ )". At this stage, the crystal lattice shrunk in the basal plane and expanded in the c-direction.

(iii) Finally in the third range of creep temperatures, solid solution of single phase " $\beta$-phase(rich in Sn)" was formed, so that the crystal lattice gradually retains its original lattice parameters $\left(a_{0}, c_{0}\right)$. Figure $10 \mathrm{c}$ illustrates the relation between creep temperatures at the three stages and the ratio "c/a" which confirms again the changes occurred in the three stages and indicates the two transition temperatures at "328 and 361K". 
The integral intensity "I" and the half line width " $\Delta 2 \theta$ " for the crystallographic planes (220) and (301) as a function of creep temperatures confirm the two transition temperatures (Fig.(11)). The integral intensities are always lower than those for the uncrept samples which confirm the dislocation mechanism expected. More defects are observed in the (301) plane due to the expansion in the c-direction.
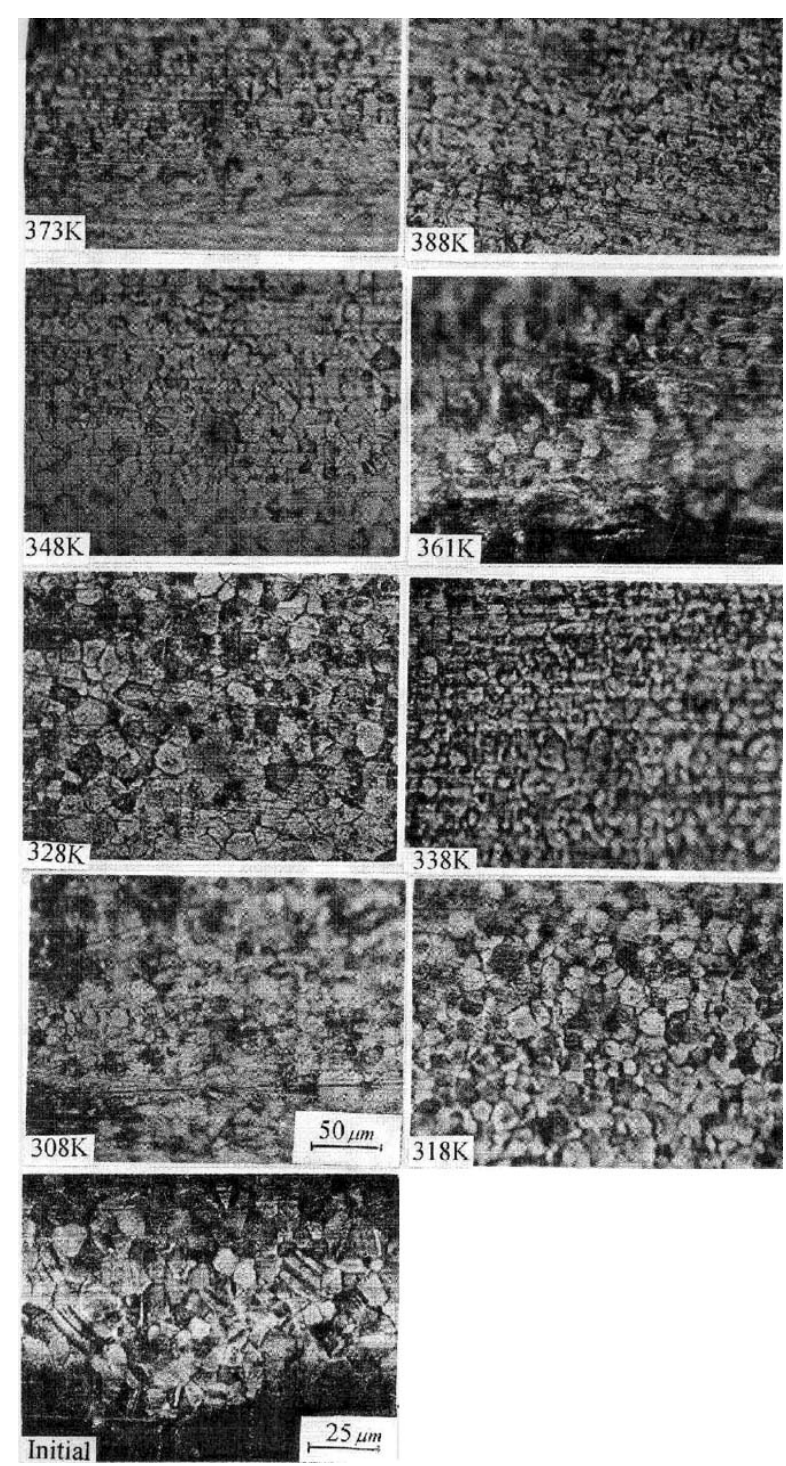

Fig.(6a) : Micrographs for Sn-5wt.\%Bi alloy samples uncrept and crept under constant applied stress of $20.5 \mathrm{MPa}$ and different creep temperatures. 


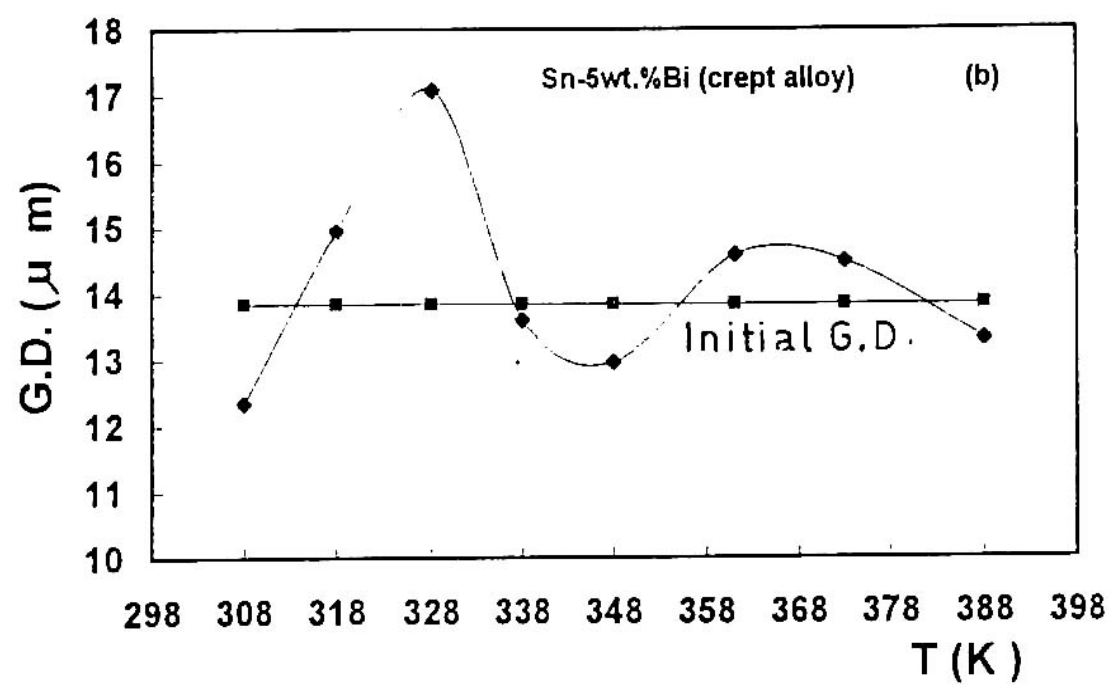

Fig.(6b) : Dependence of the grain diameter on the mechanical process operated at different creep temperatures for Sn-5wt.\%Bi alloy.

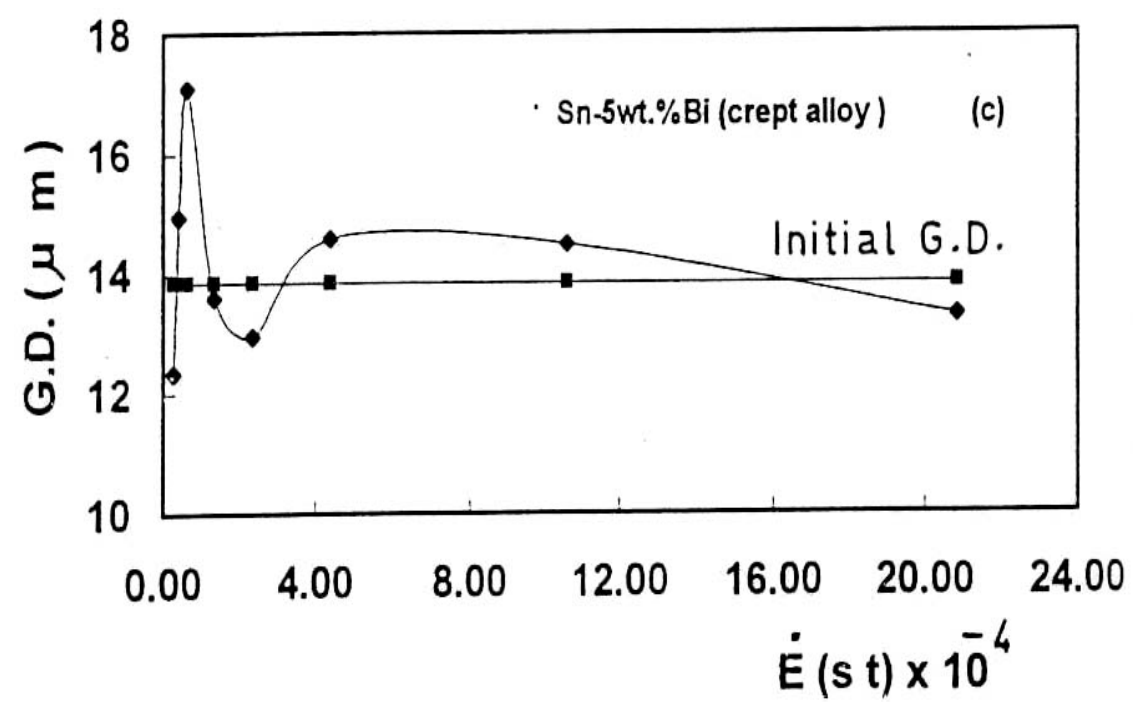

Fig.(6c) : Dependence of the grain diameter on the strain rate for Sn-5wt.\%Bi alloy samples . 

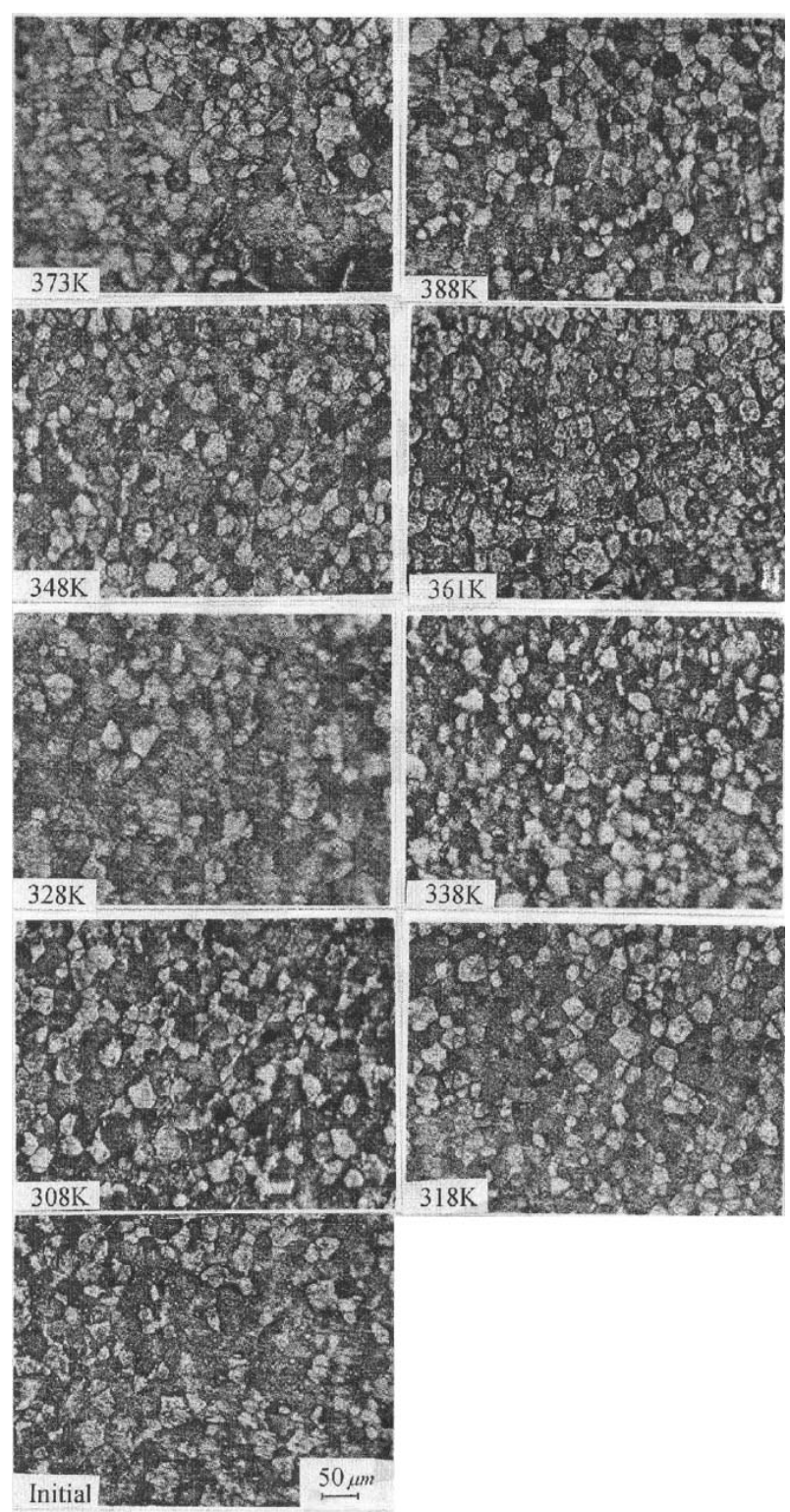

Fig.(7a) : Micrographs for Sn-5wt.\%Bi alloy samples crept under constant applied stress of $21.7 \mathrm{MPa}$ and different creep temperatures (aged for 3 years). 


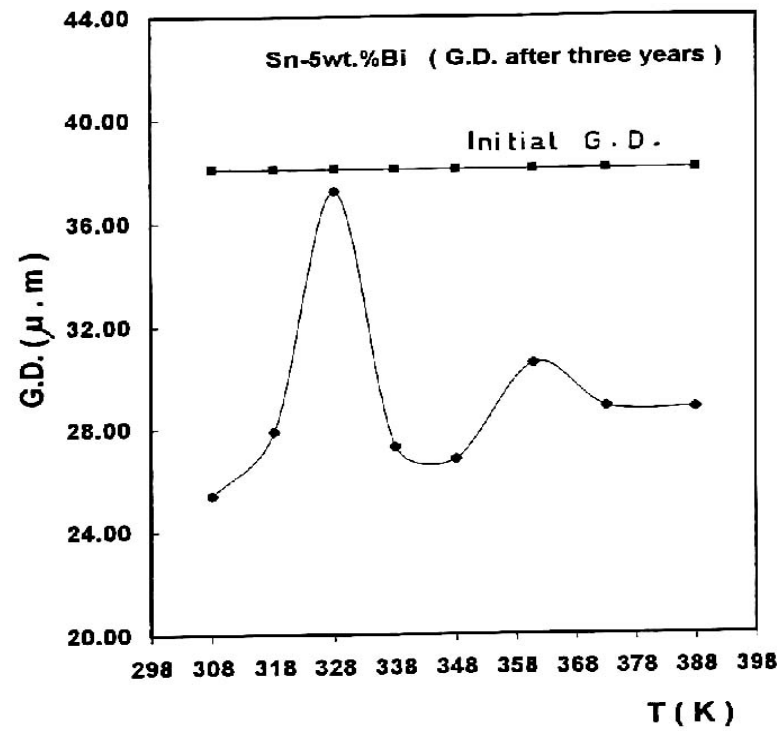

Fig.(7b) : Effect of aging time on the grain diameters of Sn-5wt.\%Bi alloy as a function of creep temperatures (aged for 3 years).

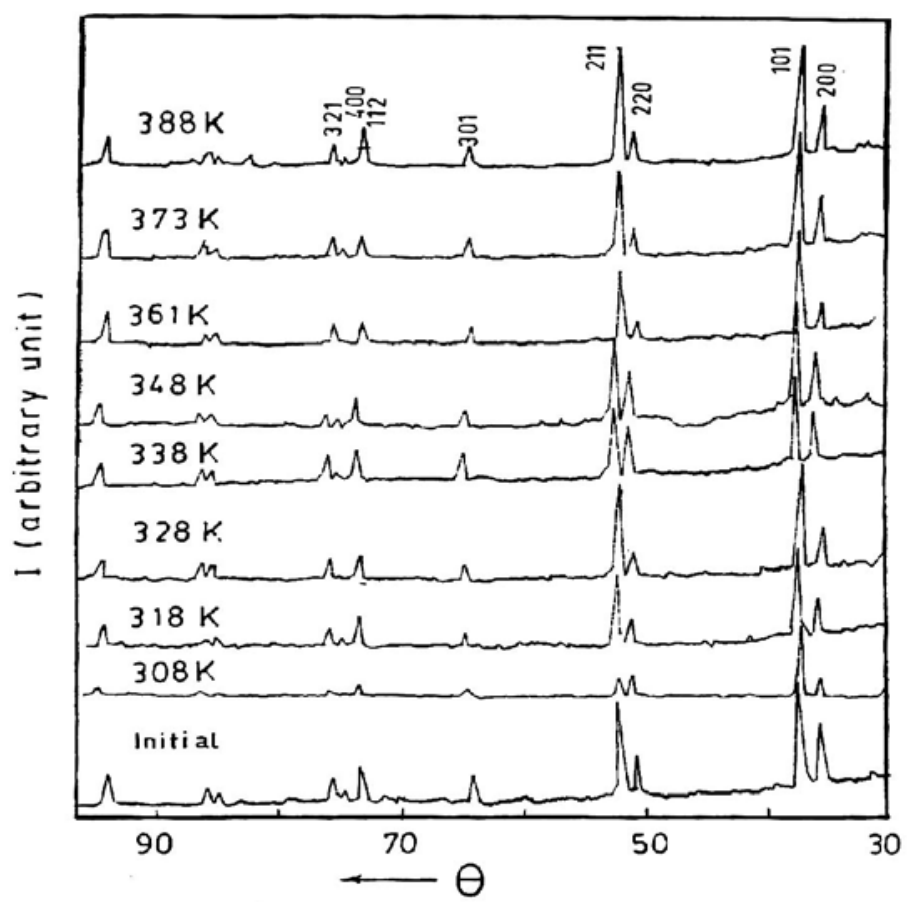

Fig.(8) : x-ray diffractograms of Sn-5wt.\%Bi alloy undeformed and deformed during creep process. 

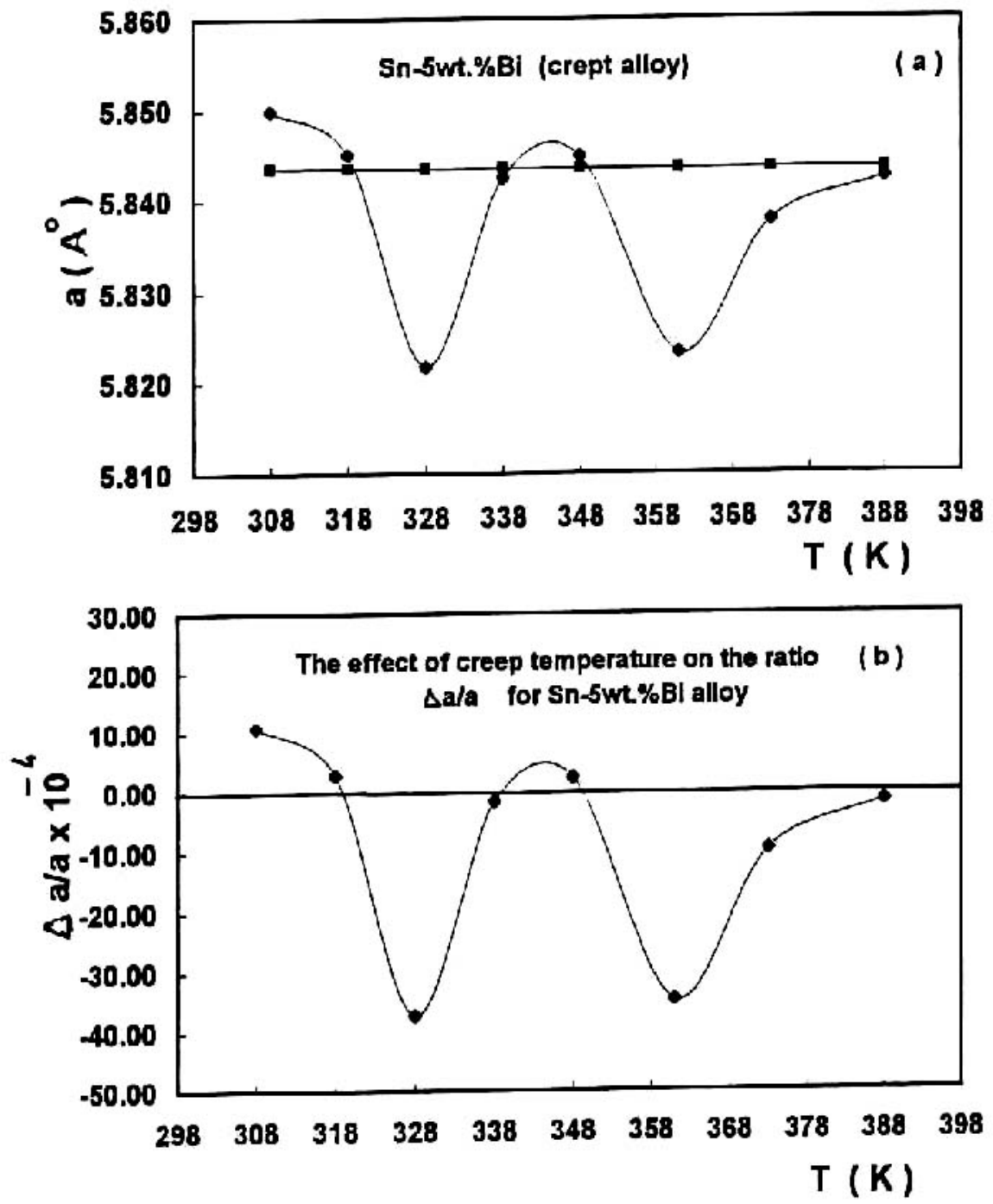

Fig.(9a,b): The effect of creep temperatures on the lattice parameter "a" and the residual lattice strain “ $\frac{\Delta a}{a}$ ” for Sn-5wt.\%Bi alloy. 

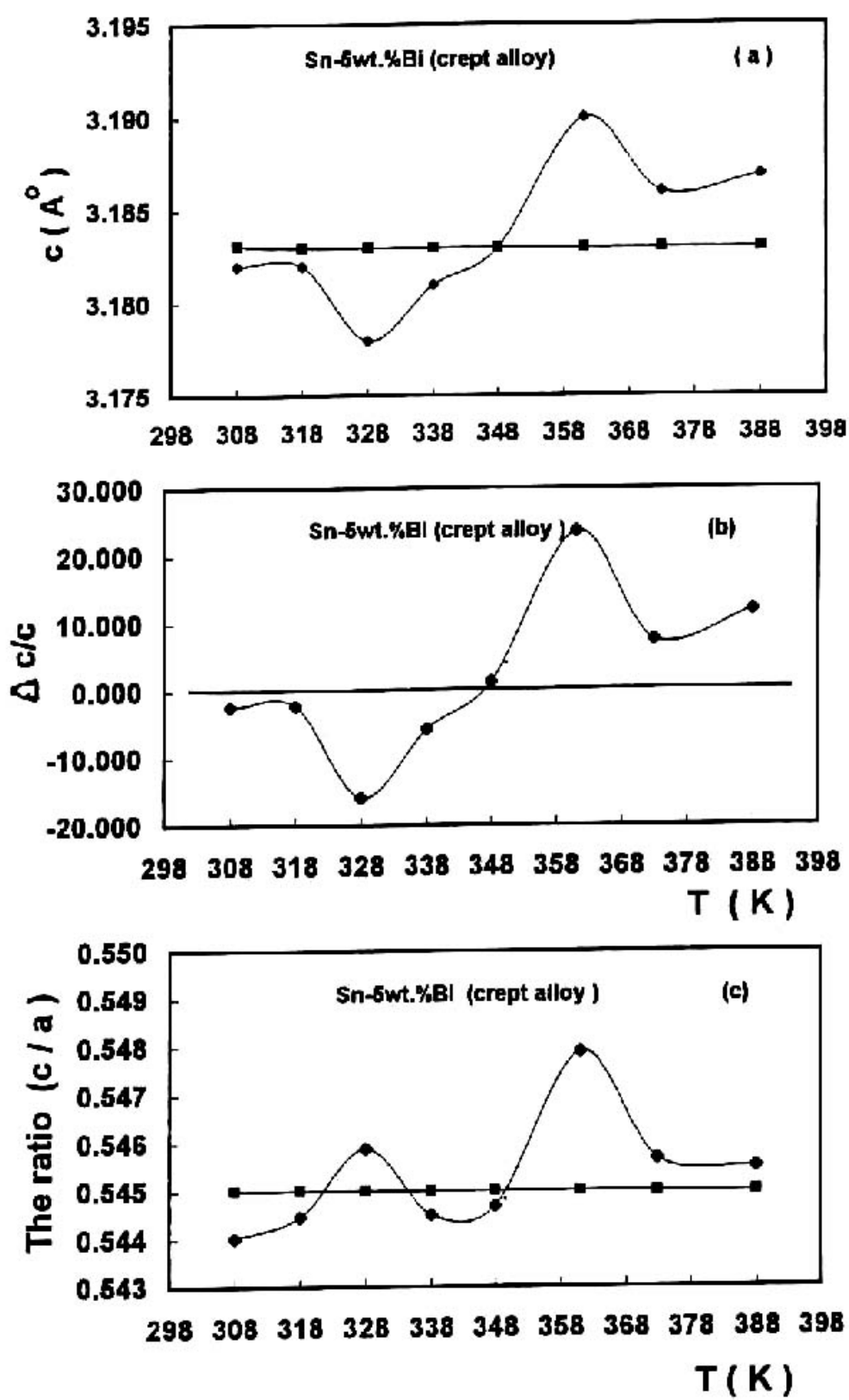

Fig.(10a.b,c): The effect of creep temperatures on each of the lattice parameter "c" and the residual lattice strain " $\frac{\Delta c}{c}$ ” and the ratio "c/a" for $S n-5 w t . \% B i$ alloy. 

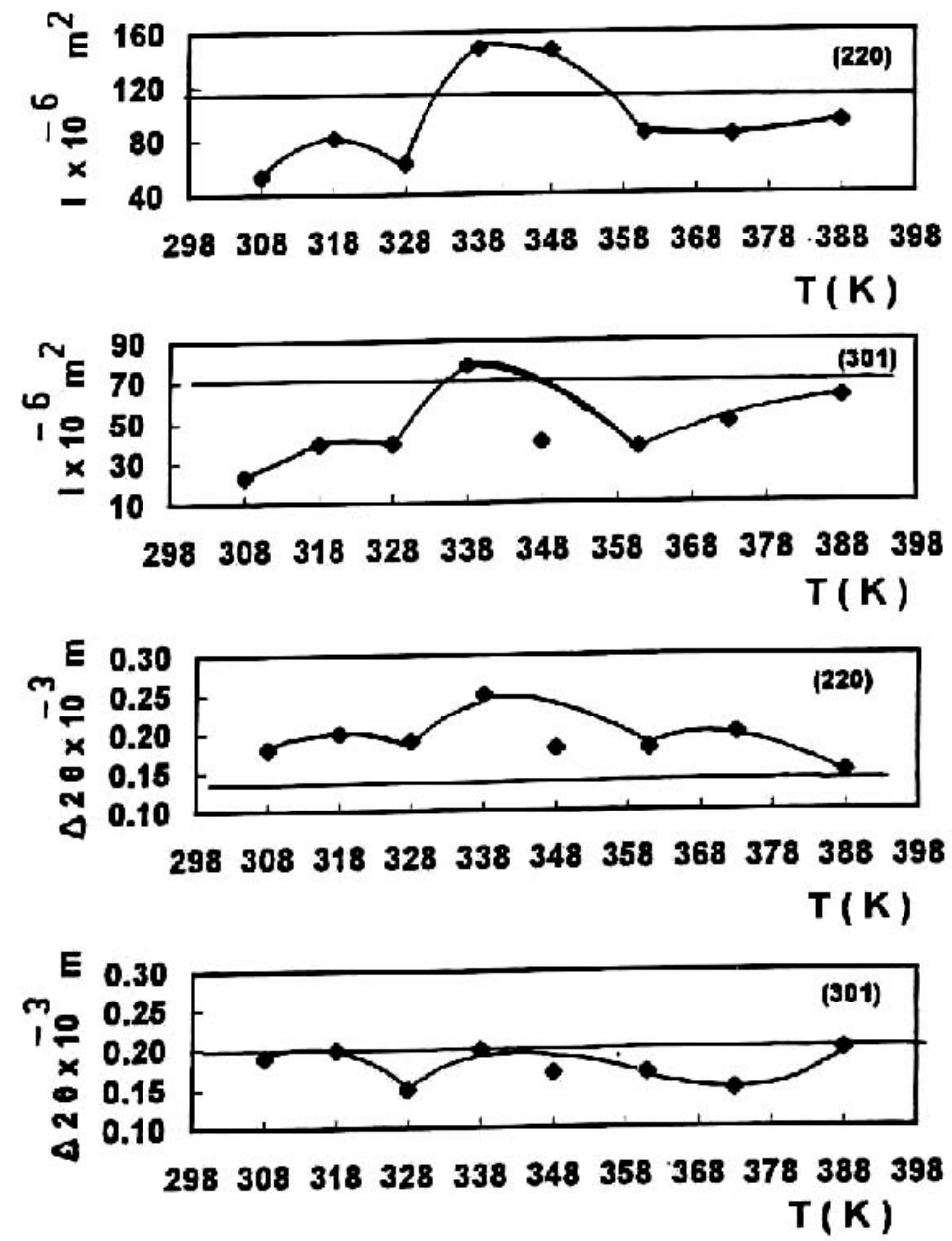

Fig.(11) : The effect of creep temperatures on the integral intensity "I" and the half line width " $\Delta 2 \theta$ ” of some x-ray crystallographic planes of Sn-5wt.\%Bi alloy.

\section{Conclusion:}

The mechanical properties and structural analysis of the Sn-5wt.\%Bi alloy deformed under the creep conditions were found to follow three ranges. In the first range, where the creep temperatures were between "308-328K" " $\alpha$-phase "(rich in $\mathrm{Bi}$ ) is existed. In the second range, where the creep temperatures were between "328-361K" “ $\alpha+\beta$ ” phases are given. In the third 
range at which the creep temperatures were in the range "361-388K", only " $\beta$ - phase" (rich in Sn) is shown.

The activation energies confirmed two mechanisms; G.B.S. with partially diffusion and the dominant mechanism which is the cross slipping mechanism.

All the x-ray parameters (a, c, $\frac{\Delta a}{a}, \frac{\Delta c}{c}, \mathrm{c} / \mathrm{a}, \mathrm{I}, \Delta 2 \theta$ ) and the grain diameters identified the changes occurred at the three ranges and at the transition temperatures (328 and 361K).

Aging of the alloy samples for three years at room temperatures, doubled the size of the grains and caused the loss of superplasticity characters.

\section{References:}

1. M. A. Ruggiera, D. W. Rutter, Mater. Sci. Technol., 11, 136, (1995).

2. K. Higshi, T. Ohnishi and Y. Nakatami, Scripta Metall., 19, 821, (1985)

3. J.A. Hines, A.A. Chokshi, "Superplasticity in advanced materials: ICSAM94”, Ed T.G. Langdon, 421; Trans Tech publications, Aedermannsdorf, Switzerland, (1994).

4. M.S. Soliman, Scripta Metallurgica et Materialia, 33, 6, 919, (1995)

5. H.E. Cline and T.H. Alden, Trans. of the Metallurgical Socity of Aima, 239, 710, (1987).

6. T.H. Alden, Acta Metallurgica, 15, 469, (1967).

7. A.M.S. Guthrie, D.E. Newbury and P.M. Hazzledine, Scripta Metallurgica, 6, 841, (1972).

8. R.Z. Valiyev, A.K. Emaletdinov, O.A. Kaibyshav and N.K. Tsenev, Phys. Metals, 6, 1008, (1985).

9. G. Saad, F. Abdel-Salam and M.T. Mostafa, Surface Technol., 22, 73, (1984).

10. S.A. Larin, V.W. Perevezenteev and K.N.Chuvil' Deyev, Fiz. Metal. Metalloved, 6a, 180, (1990).

11. S. Pattanaike, V. Raman, IBM Conference: Material development in Microelectronic Packaging, Performance and Reliability, Montreel, Quebec, Canada, 19-Aug.(1991).

12. Sueyoshi-Hidekazu and Ohzono-Yoshihisa, Nippon-Kinzoku-Gakkaishi, 55, 4, 481, (1991).

13. G.S. Al-Ganainy, M.R. Nagy, B.A. Khalifa and R. Afify, Phys. Stat. Sol.(a), 158, 463, (1996).

14. G.S.Al-Ganainy, M.R.Nagy, B.A.Khalifa and R.Afify, Egypt. J. Sol., 25(1), (2002). 
15. D. Miltin, C.H. Raedu, R.W. Messlar, J. Metall., Mater. Trans.A. Phys. Metall. Master. S.G. (USA), 30A, 1, 115, (1999).

16. M. Braunovic and C.W. Haworth, J. Appl. Phys., 40, 3459, (1969).

17. B.D. Cullity, Elements of $x$-ray diffraction, Addison-Wesley Publishing Company, Inc., Reading, Massachusetts, U.S.A., London, (1959).

18. D.L. Holt and W.A. Backofen, Trans., ASMSQ, 59, 775, (1966).

19. M.M. El-Sayed, F. Abdel-Salam, R.Abdel-Hasseb and M.R.Nagy, Phys. Stat. Sol.(a),144, 329, (1994).

20. R.E. Smallman, Modern Physical Metallurgy Butter Worth-Heinsmann Ltd, 445, (1985).

21. R. Arrowood, Materials Sci and Engineering, 92, 23, (1987).

22. L. Rotherham, A. Smith and G.Greenough, J. Inst. Metals 79, 439, (1951). 